\title{
Experiências de aprendizagem: reflexões sobre o ensino de língua estrangeira no contexto escolar brasileiro
}

\author{
Mariney Pereira Conceição \\ Universidade de Brasília
}

\begin{abstract}
O objetivo deste trabalho é refletir a respeito do ensino de língua estrangeira (inglês) oferecido em escolas de Ensino Médio brasileiras, através de uma análise de relatos de experiências de aprendizagem de alunos de graduação sobre sua aprendizagem da língua inglesa. Cinqüenta e um informantes participaram do estudo. Os instrumentos da coleta de dados foram um questionário escrito e entrevistas orais semi-estruturadas. Os resultados da análise sugerem que os professores ainda utilizam uma abordagem tradicional de ensino, através da tradução de textos e listas de palavras para memorização.
\end{abstract}

This paper aims at discussing the teaching of English in Brazilian high schools through the analysis of students' learning experiences. Participants in the research were 51 students and data were gathered through a written questionnaire and oral interviews. Results suggest that teachers use a traditional approach of teaching, based on translating and memorizing lists of words.

\section{Introdução}

Em artigo intitulado "O ensino de línguas no Brasil de 1978. E agora?", publicado nos Anais do VI Congresso Brasileiro de Lingüística Aplicada, Almeida Filho (2001) traça uma retrospectiva histórica do ensino de língua estrangeira (LE) no Brasil, constatando que, apesar dos vinte e três anos da introdução da Abordagem Comunicativa ${ }^{1}$ no país, o ensino

\footnotetext{
${ }^{1}$ Os princípios da Abordagem Comunicativa, desenvolvida a partir do modelo de competência comunicativa de Canale \& Swain (1980), incluem a integração das quatro habilidades (ouvir, falar, ler e escrever), tendo como pressuposto a inter-relação entre língua e comunicação. Almeida Filho (2001) considera que os debates a respeito da Abordagem Comunicativa tenham se iniciado no Brasil no ano de 1978, tendo como marco um seminário sobre o ensino nocional-funcional, organizado pelo curso de Letras da Universidade Federal de Santa Catarina.
} 
de LE no contexto escolar brasileiro é ainda marcado por uma tradição de aprender e ensinar fortemente arraigada entre professores e alunos, baseada em métodos tradicionais e estruturais de ensino.

Vários fatores parecem contribuir para esse cenário, entre os quais, segundo o autor, a falta de um conhecimento mais profundo dos pressupostos da abordagem comunicativa por parte dos professores, a ausência de um desempenho comunicativo na língua-alvo, o estabelecimento de uma realidade bastante distinta, não só nas diferentes regiões do país, mas também nos diferentes contextos de ensino público e privado, e, ainda, um problema no processo de formação de professores que, como reitera Almeida Filho (2001), não busca incentivar, de forma continuada, uma reflexão da prática, de maneira que esta seja sustentada em ações teoricamente bem informadas.

Os resultados da investigação conduzida em minha tese de doutorado (CONCEIÇÃO, 2004), defendida na Universidade Federal de Minas Gerais, confirmam também essa realidade em que teoria e prática se distanciam no cenário de ensino e aprendizagem de LE nos contextos escolares brasileiros. O estudo, uma proposta de investigação da aprendizagem de vocabulário, na qual as relações entre as experiências de aprendizagem dos informantes, suas crenças e suas ações ${ }^{2}$ na aprendizagem são consideradas, aponta uma perpetuação de conceitos de ensino da Abordagem Tradicional ou Gramática e Tradução, ainda presente em nossas salas de aula, através de um ensino focado na leitura e interpretação de textos, uso do dicionário, tradução e listas de palavras para memorização.

Diante dessas considerações, o objetivo deste trabalho é propor uma reflexão sobre o ensino de LE (inglês) em contextos escolares no Brasil, por meio de uma análise dos relatos das experiências de aprendizagem levantados no estudo supracitado. Apresento, na seção

\footnotetext{
${ }^{2}$ Ação, aqui, refere-se à maneira como os alunos percebem e interpretam sua aprendizagem e às estratégias de aprendizagem que adotam (HORWITZ, 1987; OXFORD, 1990). A acepção de ação que se toma, neste estudo, foi proposta por Dewey (1933), que caracterizou ação como proposital e intrinsecamente relacionada com o pensamento. O termo ação é também utilizado, neste trabalho, para se referir à prática do professor, considerando-se as ações (ou práticas), conforme Dewey (op. cit.), como relacionadas ao pensamento e inseridas em um contexto.
} 
que se segue, a justificativa teórica para o estudo, definindo termos e os principais conceitos que servirão como ponto de partida para a reflexão acerca do ensino de LE no contexto escolar brasileiro aqui proposta. São discutidas, inicialmente, questões relacionadas às experiências de aprendizagem, como o conceito de experiências e suas relações com as ações dos aprendizes na aprendizagem. Na seqüência, procuro traçar um breve panorama do ensino de LE no Brasil nos últimos anos.

\section{Experiências de aprendizagem}

De acordo com Dewey (1938, p. 111, citado por BARCELOS, 2000, p. 15), "ensinar e aprender são processos contínuos de reconstrução de experiências". ${ }^{3}$ Dewey (1933) define experiências como a interação e a adaptação dos indivíduos ao contexto em que estão inseridos. Segundo o autor, dois princípios são essenciais na constituição das experiências: o princípio da interação e o princípio da continuidade. O primeiro refere-se à interação do indivíduo com outros indivíduos e com o meio. Nessa interação, o indivíduo não só passaria por transformações, como também efetuaria transformações. O princípio da continuidade, por sua vez, refere-se à conexão entre experiências passadas e futuras. Para o autor, toda experiência contém algo do passado e modifica as experiências futuras.

Miccoli (1997) destaca que uma análise da experiência de aprendizagem dos alunos permite uma compreensão mais clara dos eventos na sala de aula. Para a autora, a aprendizagem de uma língua deve ser compreendida como uma construção e interpretação das experiências de aprendizagem. A autora ressalta, ainda, que, conhecendo as experiências de aprendizagem de seus alunos, o professor pode desenvolver uma compreensão das questões com as quais estes se defrontam na aprendizagem, podendo, assim, adaptar o ensino conforme as necessidades de seus alunos.

\footnotetext{
${ }^{3}$ Do original em inglês: "[...] teaching and learning are continuous processes of reconstruction of experience." (As traduções no corpo do texto foram feitas pela autora).
} 
Miccoli (1997) classifica as experiências de aprendizagem em experiências diretas, que se referem às experiências vividas em sala de aula, e indiretas, relativas às experiências externas à sala de aula, incluindo as experiências que os alunos tiveram no passado. Neste estudo, o termo experiência de aprendizagem é utilizado para se referir às experiências passadas ou experiências anteriores de aprendizagem, incluindo o contexto educacional, social e cultural em que essas experiências se desenvolveram.

Nos últimos anos, pesquisadores têm discutido a respeito da maneira como as experiências contribuem para a formação de crenças sobre a aprendizagem (HORWITZ, 1987, 1988; SCHOMMER, 1990; STODOLSKY, 1988). Para Schommer (op. cit.), muitas das crenças dos alunos a respeito do conhecimento e da aprendizagem advêm de sua experiência anterior de aprendizagem. Stodolsky (op. cit.) destaca que as crenças a respeito da melhor maneira de adquirir conhecimentos estão diretamente ligadas às experiências adquiridas por meio da exposição a diferentes métodos, em diferentes contextos.

Elbaum, Berg e Dodd (1993) analisaram as influências da experiência anterior de aprendizagem no uso de estratégias ${ }^{4}$ na aprendizagem de línguas, concluindo que as experiências individuais de aprendizagem, tanto dentro, quanto fora do contexto escolar, influenciam a formação de crenças em relação às estratégias de aprendizagem e sua eficácia. O estudo mostra o impacto da experiência anterior dos alunos, não apenas na formação das crenças mas também no uso das estratégias, revelando, ainda, que as crenças dos alunos a respeito da eficácia de determinadas estratégias relacionam-se às oportunidades que os alunos tiveram de utilizar, na sua experiência anterior, diferentes estratégias.

Segundo Elbaum, Berg e Dodd (op. cit.), é imperativo que as experiências anteriores de aprendizagem dos alunos sejam analisadas com mais cuidado e atenção na pesquisa em Lingüística Aplicada (LA). Os autores sugerem que as experiências de aprendizagem estão inseridas em diferentes contextos ou práticas de culturas, que transmitiriam mensagens aos aprendizes a respeito da eficácia de determinadas estratégias. Essas

\footnotetext{
${ }^{4}$ Oxford (1990, p. 8) define estratégias de aprendizagem como ações específicas do aprendiz para tornar a aprendizagem mais fácil, auto-direcionada, efetiva e mais facilmente aplicável a situações novas.
} 
mensagens seriam transmitidas através dos métodos utilizados pelo professor, das atividades realizadas em sala de aula e da avaliação. Os autores avançam ainda em suas conclusões a respeito do assunto, destacando que "mesmo dentro das escolas, existem práticas de culturas completamente diferentes" (ELBAUM; BERG; DODD, 1993, p. 330). ${ }^{5}$

A meu ver, no entanto, o estudo supracitado limita-se a investigar os tipos de experiência anterior de aprendizagem dos informantes (programas tradicionais de instrução formal ou programas de imersão), não se aprofundando na análise da experiência, considerando-se os paradigmas em que se circunscrevem as práticas do professor, os métodos utilizados ou, ainda, as atividades realizadas em sala de aula.

As experiências de aprendizagem deveriam ser consideradas com mais atenção nas pesquisas de aprendizagem de LE. Acredito que muitas das ações e mesmo dificuldades dos alunos poderiam ser explicadas a partir de uma compreensão mais profunda dessas experiências e da maneira como elas podem influenciar a aprendizagem. A história de aprendizagem dos alunos pode ter um efeito, não só na utilização de estratégias mas também na motivação dos alunos para a aprendizagem. $\mathrm{Na}$ verdade, não só as pesquisas na área de ensino e aprendizagem de línguas deveriam considerar a questão das experiências de aprendizagem com mais atenção mas também cada professor, como um pesquisador em sala de aula, deveria estar atento a essa questão, procurando conhecer melhor seus alunos e as experiências de aprendizagem de línguas que tiveram no passado, guiando-os a uma reflexão crítica dessas experiências.

\section{O ensino de línguas estrangeiras no Brasil}

Segundo Almeida Filho (2001), existe, no Brasil, uma tradição de aprender e ensinar, geralmente baseada em métodos da abordagem gramatical, já arraigada entre professores e alunos, bem como uma tradição de resistência a inovações na situação de ensino e aprendizagem. O autor aponta um enorme distanciamento entre teoria e prática, no que se refere ao ensino de LE nas escolas brasileiras. Para Almeida Filho (op. cit., p. 23), "há uma grande diferença no Brasil entre o que se pratica de ensino de

\footnotetext{
${ }^{5}$ Do original em inglês: "[...] even within schools there exist widely disparate
} cultures of practice." 
línguas nas escolas e salas de aula e o que projetam acadêmicos, teóricos e pesquisadores no cenário universitário dos cursos de Letras e programas de pós-graduação em LA, Letras e Estudos da Linguagem."

Segundo o autor, vários fatores compõem a realidade do ensino de línguas estrangeiras no Brasil, colaborando para essa cena cotidiana em sala de aula, em que teoria e prática se distanciam. Em primeiro lugar, essa realidade é bastante distinta, não só nas diferentes regiões do país mas também nos diferentes contextos de ensino público e privado. Além disso, existe um problema no processo de formação de professores, que não busca incentivar, de forma continuada, uma reflexão da prática, de maneira que esta seja sustentada em ações teoricamente bem informadas. Outro fator a se considerar, segundo Almeida Filho (2001), seria também o fato de os professores não apresentarem, muitas vezes, um desempenho comunicativo na língua-alvo, sentindo-se desestimulados a ensinar de maneira comunicativa.

Neves (1996) retrata também a questão do ensino/aprendizagem de LE no Brasil, destacando que mitos de abordagens tradicionais e estruturais ainda interferem na prática da sala de aula. Para a autora, existe, no Brasil, um conceito cristalizado na mente, tanto do aprendiz quanto dos professores, de que só se aprende LE através da aquisição da competência gramatical ou lingüística. O conceito amplo de competência comunicativa, ${ }^{6}$ incluindo as competências sócio-lingüística, discursiva e estratégica, ainda não é considerado pelos professores. Os resultados desse estudo apontam, ainda, para o fato de que os professores, mesmo quando utilizam um material considerado comunicativo, o fazem ainda de forma muito estrutural, utilizando técnicas baseadas nas abordagens estrutural e tradicional.

Outro dado relevante na pesquisa (NEVES, op. cit.) é que o professor de LE no Brasil parece considerar-se responsável pela aprendizagem do aluno, assumindo uma atitude autoritária, conduzindo a aula de maneira centrada no professor. O aluno, por sua vez, se mostra acostumado a ser guiado e espera explicações feitas através de aulas expositivas.

\footnotetext{
${ }^{6}$ Cf. o modelo de competência comunicativa de Del Hymes, que compreende a integração de sistemas de competência gramatical, psicolingüística, sociocultural e probalistica (SAVIGNON, 1983) e que, como mencionado anteriormente, veio a ser sistematizado por Canale e Swain (1980).
} 
Percebe-se, pois, a partir dessas considerações, a necessidade de pesquisas que investiguem mais profundamente as experiências de aprendizagem dos alunos nos contextos de sala de aula de LE no Brasil, buscando, através do levantamento dessas experiências, refletir sobre o ensino oferecido nas escolas brasileiras.

\section{Objetivos}

O objetivo deste estudo será, através do levantamento de relatos de experiências de aprendizagem dos informantes, fazer uma reflexão sobre o ensino de língua estrangeira (inglês) em contextos escolares de Ensino Médio (EM) brasileiros.

\section{Metodologia}

A pesquisa se configura como um estudo de caso. Segundo Johnson (1992), os estudos de caso são a) naturalistas, já que o procedimento de coleta é realizado no ambiente natural em que o estudo é realizado; b) descritivos, pois descrevem um fenômeno. Contudo, podem ir além da descrição, passando à interpretação de um contexto ou cultura; c) longitudinais, pois realizam-se em períodos longos de observação. Alguns estudos de caso, porém, são de curta duração; d) qualitativos, apesar da possibilidade de proverem informações de caráter quantitativo. Ainda segundo Johnson (op. cit.), o estudo de caso é definido a partir da unidade de análise, que pode ser um professor, uma sala de aula, uma escola, uma agência, uma instituição ou uma comunidade. Podem ser investigados um ou vários casos específicos, sendo o número de casos sempre pequeno, permitindo uma análise criteriosa.

Neste estudo, ambas as abordagens, qualitativa e quantitativa, foram utilizadas. A pesquisa qualitativa, segundo Larsen-Freeman e Long (1991), caracteriza-se por uma preocupação com o comportamento humano, a partir da referência do próprio indivíduo, através da utilização de questionários e entrevistas orais. Esse tipo de pesquisa, conhecida como naturalista ou interpretativa, considera a aquisição não como um fenômeno isolado, mas inserido nos contextos sócio-culturais em que ela ocorre (DAVIS, 1995). 
Johnson (1992, p. 34) destaca que “... a distinção quantitativo/ qualitativo, como qualquer outra dicotomia, não caracteriza adequadamente a pesquisa". ${ }^{7}$ Para a autora, mesmo os estudos de caráter qualitativo etnográfico podem incluir dados quantitativos. Ainda, para Scaramucci (1995), a distinção qualitativo/quantitativo e a tendência de se optar por um aspecto, evitando-se completamente o outro, pode, na verdade, obscurecer ou dificultar a elucidação de variáveis importantes na pesquisa. Segundo a autora, a pesquisa qualitativa pode envolver técnicas quantitativas e vice-versa, pois o conhecimento quantitativo está presente em avaliações qualitativas, da mesma maneira que o conhecimento qualitativo está presente em avaliações quantitativas.

\section{O contexto em que o estudo foi realizado}

Cumpre reiterar que este artigo se baseia em um estudo de caso maior (CONCEIÇÃO, 2004), sendo os dados relativos às experiências de aprendizagem dos informantes levantados nesse estudo utilizados aqui para uma reflexão sobre o ensino de língua inglesa oferecido em contextos de EM em escolas brasileiras. A coleta de dados do estudo de caso mencionado foi realizada em uma turma de Língua Inglesa Instrumental de um curso de graduação em uma universidade pública do estado de Minas Gerais, tendo sido solicitado aos alunos que relatassem suas experiências de aprendizagem de língua inglesa durante o EM. As experiências de aprendizagem aqui apresentadas foram relatadas por alunos que cursaram o EM no estado de Minas Gerais, tendo concluído o curso nos anos de 2000 e 2001.

\section{Os informantes}

Os informantes da pesquisa foram cinqüenta e um alunos universitários, estudando inglês como língua instrumental (Inglês Instrumental I), no curso de graduação em Engenharia Elétrica da Universidade Federal de Minas Gerais, tendo cursado o EM em escolas

\footnotetext{
${ }^{7}$ Do original em inglês: "[...] the quantitative versus qualitative distinction, like any other dichotomy, does not adequately characterize research."
} 
particulares (73,0\% dos informantes) e em escolas públicas (27,0\%), na cidade de Belo Horizonte (Minas Gerais) e região. Em sua grande maioria, eram do sexo masculino (94,0\%), com idade média de 19 anos e meio.

\section{A coleta de dados}

A coleta de dados foi realizada no primeiro semestre letivo de 2002. A turma de língua inglesa que serviu de cenário para a pesquisa mantinha 02 (dois) encontros semanais de uma hora e quarenta minutos cada. A coleta iniciou-se na primeira semana de aula e foi realizada dentro de um período de 05 (cinco) semanas.

\section{Instrumentos da coleta de dados}

Dois instrumentos foram utilizados para o levantamento dos dados relativos às experiências de aprendizagem dos informantes: um questionário escrito (QCE A - questões 09 a 12 - Anexo A) e entrevistas individuais (EI - Anexo B). ${ }^{8}$

No QCE A, as questões de 01 a 07 referem-se especificamente ao perfil dos informantes, sendo as questões de 01 a 04 de identificação do aluno, como nome, idade, escola em que cursou o Ensino Médio (escola pública ou particular) e ano de conclusão do curso. A questão 05 refere-se à exposição do aluno à língua-alvo em cursos de idiomas e, ainda, o tempo dessa exposição. As questões de 09 a 12 referem-se, especificamente, ao levantamento da experiência de aprendizagem de língua inglesa do aluno durante o EM, incluindo a descrição dessa experiência, assim como as atividades realizadas com mais freqüência na sala de aula. Para a verificação da consistência das respostas dos

\footnotetext{
${ }^{8}$ Como mencionado anteriormente, o estudo aqui apresentado se baseia em um estudo de caso maior (CONCEIÇÃO, 2004). Portanto, foram discutidos e apresentados como anexos neste trabalho apenas os itens do questionário escrito e da entrevista que se referem ao levantamento das experiências de aprendizagem dos alunos.
} 
informantes a esses itens, foi solicitado aos alunos, no item 12, que mencionassem aspectos na experiência de aprendizagem no EM que os alunos não gostariam de ver repetidos na universidade. O QCE A foi aplicado no terceiro dia da coleta de dados (terceira aula do curso) e o tempo para preenchimento foi de trinta minutos.

Na coleta de dados, foram também utilizadas entrevistas individuais semi-estruturadas. Conforme Nunan (1992), entrevistas orais têm sido amplamente utilizadas como instrumentos de pesquisa em LA, sendo as entrevistas semi-estruturadas as preferidas pelos pesquisadores que trabalham com a pesquisa interpretativa, justamente por oferecer um grau de controle, combinado a uma certa flexibilidade. Nas entrevistas semiestruturadas, o pesquisador tem uma idéia daquilo que deseja saber e, assim, tópicos e assuntos determinam o curso da entrevista, ao invés de perguntas fixas.

Para Nunan (op. cit.), o pesquisador deve selecionar uma amostra representativa de informantes, utilizando-se critérios conforme as variáveis do estudo. Como esta pesquisa contava com a participação de um grande número de informantes (51), 22 alunos (43,0 \% dos informantes) foram entrevistados. As EI foram conduzidas fora do horário das aulas, por questões relacionadas à carga horária do curso e do conteúdo programático a ser cumprido, tendo sido realizadas após a aplicação do questionário, nas terceira, quarta e quinta semanas da coleta. O tempo de duração das entrevistas foi de aproximadamente quarenta minutos cada. Todas as entrevistas foram gravadas com a permissão dos informantes.

\section{Procedimentos para a análise dos dados}

Na tabulação dos dados obtidos por meio de questões abertas do questionário e das entrevistas, as respostas foram agrupadas em categorias (NUNAN, 1992), registrando-se a reincidência das respostas e tabulando-se o número de alunos que as responderam ou o número de vezes que cada tipo de resposta foi mencionada.

O critério utilizado para testar a confiabilidade das categorias geradas foi o critério denominado regrounding, sugerido por Seliger e Shohamy (1990). Esse critério, comumente utilizado na pesquisa qualitativa, consiste em voltar aos dados por uma segunda vez e comparar os resultados de 
uma segunda análise com os resultados da primeira, buscando-se padrões, categorias ou aspectos comuns nas duas análises.?

\section{Apresentação e discussão dos resultados}

Sendo a proposta deste estudo uma reflexão sobre o ensino de LE (inglês) nos contextos escolares de EM, através de uma análise de experiências de aprendizagem relatadas por alunos, apresento, a seguir, os dados relativos a essas experiências. No intuito de atingir os objetivos da análise, duas perguntas de pesquisa mais específicas foram propostas:

1) Como os informantes avaliam e caracterizam sua experiência de aprendizagem de língua estrangeira (inglês) durante o EM?

2) Quais eram as atividades realizadas com mais freqüência na sala de aula de língua inglesa no EM?

Na seqüência, apresento e discuto, inicialmente, os resultados do questionário escrito, passando, então, aos resultados das entrevistas. As questões de 09 a 12 do QCE A tinham como objetivo levantar relatos acerca da experiência de aprendizagem de língua inglesa no EM por parte dos informantes, assim como das atividades realizadas com mais freqüência na sala de aula. Na questão 09 foi solicitado aos informantes que descrevessem sua experiência de aprendizagem de língua inglesa. Ao descreverem suas experiências, os alunos as avaliaram como negativa, positiva ou regular, conforme a TAB. 1.

TABELA 1

Avaliações das experiências de aprendizagem de língua inglesa no EM

\begin{tabular}{l|c}
\hline Avaliação & $\mathrm{n}^{\circ}$ alunos \\
\hline Negativa & 37 \\
Positiva & 06 \\
Regular & 06 \\
\hline
\end{tabular}

9 Cumpre ressaltar que os resultados obtidos a partir da segunda análise realizada confirmaram os resultados da primeira análise dos dados. 
Como se pode observar na TAB. 1, a maioria dos alunos (37 alunos) avaliou sua experiência como negativa. Seis informantes a avaliaram como positiva e, ainda, seis informantes a avaliaram como regular. Na descrição das experiências, foram apresentadas as seguintes características, conforme registra a TAB. 2.

TABELA 2

Experiências de aprendizagem no EM

\begin{tabular}{l|c}
\hline \multicolumn{1}{c|}{ Características } & $\begin{array}{c}\mathrm{n}^{\text {o vezes }} \\
\text { apontadas }\end{array}$ \\
\hline Turmas heterogêneas & 21 \\
Utilização de métodos repetitivos e obsoletos & 16 \\
(listas de vocabulário, memorização de palavras, tradução) & 11 \\
Falta de comprometimento ou despreparo do professor & 10 \\
Ênfase exaustiva no vocabulário & \\
\hline
\end{tabular}

Quatro fatores parecem predominar na caracterização das experiências. A heterogeneidade ${ }^{10}$ das turmas foi apontada 21 vezes. $O$ segundo fator mais apontado pelos alunos foi a utilização de métodos repetitivos e obsoletos, como a memorização de palavras isoladas, listas de vocabulário e tradução (16 vezes). Foram também mencionados fatores como a falta de comprometimento ou despreparo dos professores (11 vezes) e ênfase exaustiva no vocabulário (10 vezes). ${ }^{11}$

A questão 10 tinha como objetivo o levantamento das atividades realizadas com mais freqüência na sala de aula de língua inglesa no EM. A TAB. 3 demonstra os resultados obtidos.

\footnotetext{
${ }^{10}$ Entenda-se heterogêneas em relação ao nível de conhecimento de língua dos informantes.

${ }^{11}$ Como cada informante apontou mais de um fator na caracterização de sua experiência, foi divulgado o número de vezes que cada fator foi apontado. Esse procedimento foi utilizado na apresentação dos dados neste trabalho, sempre que os informantes apontaram mais de uma resposta para as questões propostas.
} 
TABELA 3

Atividades realizadas com mais freqüência na sala de aula

\begin{tabular}{|c|c|}
\hline Atividades & $\mathrm{n}^{\mathrm{o}}$ vezes apontadas \\
\hline Interpretação de textos & 33 \\
\hline Exercícios gramaticais & 29 \\
\hline Tradução & 23 \\
\hline Listas de vocabulário & 17 \\
\hline
\end{tabular}

Como se pode observar, as atividades apontadas pelos informantes como realizadas com maior freqüência foram, em primeiro lugar, a interpretação de textos (a atividade foi apontada 33 vezes), exercícios gramaticais (apontados 29 vezes), tradução (23 vezes) e listas de vocabulário para memorização (17 vezes).

Foi solicitado ainda aos alunos, na questão 12, que apontassem aspectos na aprendizagem de língua inglesa durante o EM os quais eles não gostariam de ver repetidos na universidade. Os resultados obtidos nesse item corroboram os resultados dos itens de 09 a 11, como se pode observar na TAB. 5.

TABELA 5

Aspectos que os alunos não gostariam de ver repetidos na universidade

\begin{tabular}{l|c}
\hline \multicolumn{1}{c|}{ Aspectos } & $\begin{array}{c}\text { n.․ vezes } \\
\text { apontadas }\end{array}$ \\
\hline Utilização de métodos repetitivos e obsoletos & 23 \\
Falta de comprometimento do professor & 14 \\
Turmas heterogêneas & 10 \\
Ênfase exaustiva no vocabulário & 08 \\
Outros & 07 \\
Nenhum aspecto negativo & 02 \\
\hline
\end{tabular}

Como se pode observar na TAB. 5, a utilização de métodos julgados pelos alunos como repetitivos e obsoletos foi mencionada 23 vezes. A falta de comprometimento ou descaso dos professores em relação às aulas e à aprendizagem dos alunos foi mencionada 14 vezes, e a questão das turmas heterogêneas, 10 vezes. A ênfase exaustiva no vocabulário foi também mencionada (08 vezes) como um aspecto que os informantes não gostariam que se repetisse no Ensino Superior. Sete 
alunos mencionaram outros aspectos relacionados, por exemplo, à avaliação ou aos critérios de correção oral em sala de aula e, ainda, 02 alunos declararam que não tinham nenhum aspecto negativo a mencionar.

Observe-se, a seguir, alguns trechos extraídos dos relatos dos informantes no QCE A, no que se refere à avaliação das experiências.

[1] "(...) até eu me formar todos os meus professores tinham uma característica em comum: o descaso em ensinar".

AVB, QCEA, $09^{12}$

[2] “(...) mesmo com três anos de inglês eu não aprendi praticamente nada".

LFA, QCEA, 09

[3] "Uma experiência nada agradável. Pelos três anos, as aulas possuíam um método onde só era possível adquirir algum vocabulário (..)".

HSF, QCEA, 09

Entre os aspectos apontados pelos alunos na caracterização de suas experiências, dois fatores me chamaram a atenção. O primeiro, a questão da ênfase exaustiva no vocabulário e, o segundo, a utilização de métodos repetitivos e obsoletos para o ensino de vocabulário, como listas de vocabulário, memorização de palavras e tradução, como se pode observar nos trechos a seguir:

[4] "(...) uso de métodos que não se aprende nada (decorar palavras soltas)".

JLN, QCEA, 09

[5] "Julgo o meu conhecimento como uma aprendizagem por repetição. Apesar do grande tempo, não aprendi muito (...)".

LNS, QCEA, 09

\footnotetext{
${ }^{12}$ Nas discussões dos resultados obtidos neste estudo, apresento trechos de falas dos informantes, extraídos dos instrumentos utilizados na coleta de dados. Por questões de ética, para a apresentação desses trechos, refiro-me aos informantes através de iniciais, destacando, ainda, o instrumento e número do item do qual os trechos foram extraídos. Dado ao grande volume, esses dados não foram anexados ao trabalho, encontrando-se, no entanto, disponíveis para exame. Ressalto também que os trechos não foram editados e os desvios lingüísticos foram mantidos.
} 
[6] "Decorar lista de verbos e vocabulários gerais".

LNS, QCEA, 09

[7] "Fazer listas de vocabulário que eram muito grandes e não me ajudavam a ter nenhum ganbo no meu vocabulário em relação ao inglês".

FAG, QCEA, 09

[8] "Decorar palavras soltas, sem um contexto".

LRR, QCEA, 09

[9] "Decorar significados de palauras".

JCV, QCEA, 09

Alguns informantes declararam, inclusive, que, como não acreditavam na eficácia dos métodos utilizados, tomavam para si a responsabilidade de aprender, estudando sozinhos em casa, através da leitura de textos e da utilização do dicionário.

[10] "A maior parte do que sei aprendi sozinho lendo textos em inglês". HAR, QCEA, 09

[11] "(...) o que sei hoje, foi sozinho mesmo que aprendi, com a ajuda do dicionário”.

JLN, QCEA, 09

[12] “(...) mas como sempre procurei me aperfeiçoar, estudando sozinbo e lendo com freqüência, considero que adquiri um bom nivel (.. .)". MAF, QCEA, 09

[13] "(...) aprendi a maiorparte fora da escola, em curso e com experiência própria, como viagens, vendo filmes e ouvindo música, além de leitura”.

FFE, QCEA, 09

[14] "Devido a estes aspectos, percebi que estava em minhas mãos o estudo pelo menos da leitura em inglês".

DVV, QCEA, 09

É interessante ressaltar que, entre os cinqüenta e um informantes, apenas seis alunos registraram que sua experiência foi positiva. Esses alunos imputaram essa experiência positiva ao fato de seus professores saberem bem como utilizar métodos e técnicas de ensino que facilitavam a retenção de vocabulário na memória. 
[15] "Minha experiência de aprendizagem de inglês no colegial foi boa porque eu tive professores que trabalhavam bem as habilidades dos alunos $e$, do seu modo conseguiram forçá-los a aprender e a guardar na memória as palauras em inglês".

ABR, QCEA, 09

O segundo aspecto investigado em relação às experiências de aprendizagem diz respeito às atividades realizadas na sala de aula. Um exame das atividades desenvolvidas em sala confirmam a ênfase no vocabulário mencionada pelos alunos no item 09 (QCE A), tendo sido registradas práticas como tradução e memorização de listas de vocabulário.

Lamentavelmente, podemos observar, nos dados, elementos que parecem caracterizar uma prática baseada, em grande parte, na interpretação de textos, seguida de tradução, exercícios de gramática e listas de vocabulário, sem uma preocupação maior com o desenvolvimento da competência comunicativa, confirmando uma perpetuação das práticas do ensino tradicional de línguas, como apontam Almeida Filho (2001) e Neves (1996), ao analisarem o ensino de LE no Brasil nos últimos anos. Observem-se os relatos que se seguem.

[16] "Todos os meus professores sempre seguiam o mesmo esquema de aulas: davam um texto, pediam para que lêssemos, depois ele lia em voz alta dando o significado de algumas palavras ou traduzia ele inteiro".

GVA, QCEA, 09

[17] "(...) aulas que tinham como objetivo final chegarà tradução literal de cançôes de amor e de aprender a gramática do verbo to be, transformaram em um vício o aprendizado".

ECE, QCEA, 09

O trecho a seguir deixa claro o descontentamento de um dos informantes em relação ao uso de listas de vocabulário. O aluno sugere que o ensino das palavras deveria ocorrer levando-se em consideração o contexto em que as palavras são utilizadas.

[18] “(...) trabalhando com as palavras de um texto, e não dando somente uma lista de vocabulário".

DVV, QCEA, 09

Quanto aos dados levantados a partir do item 12 do QCE A, incluído com o objetivo de checar a consistência das respostas dos informantes em relação à sua experiência de aprendizagem, é interessante ressaltar 
a maneira como os mesmos dados levantados nos itens anteriores emergiram também nesse item, confirmando as respostas dos informantes. Os alunos referiram-se, mais uma vez, a questões como a utilização de métodos repetitivos e obsoletos para a aprendizagem de vocabulário, a ênfase exaustiva ao ensino do vocabulário, bem como a heterogeneidade das turmas e a falta de comprometimento do professor, como se pode observar no relato abaixo:

[19] "Não gostaria de aulas maçantes, repetitivas. Também não gosto de atividades de decorar, ou atividades mecânicas e repetitivas".

LAM, QCEA, 12

Tendo discutido os resultados relativos às experiências, obtidos a partir do QCE A, passo, então, aos resultados levantados a partir das EI. Apresento, na TAB. 6, os dados a respeito das atividades realizadas na sala de aula no EM.

TABELA 6

Atividades realizadas com mais freqüência na sala de aula - EI

\begin{tabular}{l|c}
\hline Atividades & $\mathrm{n}^{\underline{0}}$ vezes apontadas \\
\hline Interpretação de textos & 10 \\
Tradução & 09 \\
Exercícios gramaticais & 08 \\
Listas de vocabulário & 05 \\
\hline
\end{tabular}

Observa-se, numa análise da tabela acima, que a interpretação de textos foi apontada pelos informantes como a atividade realizada com maior freqüência na sala de aula (10 vezes). Em seguida, a tradução foi a segunda atividade apontada (09 vezes). Exercícios gramaticais foram também citados (08 vezes) e, ainda, listas de vocabulário ( 05 vezes).

É interessante notar que, assim como no QCE A, os dados relativos às atividades realizadas em sala de aula levantados a partir das EI parecem indicar a interpretação de textos, a tradução, os exercícios de gramática e as listas de vocabulário como as principais atividades desenvolvidas no EM. Vejamos, como exemplo, as seguintes falas, extraídas das EI.

[20] “(...) no colégio o que tinha mais era texto, a maioria das aulas era texto e interpretação de texto".

DJS, EI 
[21] "O que eles mandavam fazer era repassar o texto e escrever abaixo de cada linha a tradução, só depois eles liam, de novo, traduzindo". APS, EI

[22] "Eles davam uma lista de vocabulário para você decorar (...)".

RAD, EI

É também interessante ressaltar que a questão que emergiu no QCE A a respeito de os alunos, insatisfeitos com os métodos utilizados em sala, procurarem assumir por si próprios a responsabilidade em relação à aprendizagem de vocabulário, também se confirmou através das EI, como se observa na seguinte fala do aluno ALS:

[23] "(...) grande parte do que eu peguei de vocabulário foi por minha conta mesmo".

ALS, EI

Como se pôde observar, os relatos das experiências de aprendizagem de LE dos informantes durante o EM, levantados tanto através do questionário quanto das entrevistas, apontam uma experiência de aprendizagem centrada na interpretação de textos e no vocabulário, através da utilização de práticas tradicionais de ensino. Ainda nos dias de hoje, como destaca Neves (1996), métodos tradicionais parecem exercer uma grande influência na sala de aula de língua inglesa.

Considerando a importância das experiências no processo de aprendizagem de LE (MICCOLI, 1997), essa realidade no ensino de línguas no Brasil me parece bastante preocupante. Como foi discutido na seção de revisão teórica neste artigo, as experiências de aprendizagem podem transmitir aos aprendizes, através dos métodos utilizados pelo professor e das atividades realizadas em sala de aula, certas mensagens em relação à eficácia de determinadas estratégias de aprendizagem, mensagens essas que influenciariam, segundo Elbaum; Berg e Dodd (1993), as ações dos aprendizes na aprendizagem. Nesse caso, a utilização de uma abordagem tradicional pelo professor em sala de aula poderia transmitir aos alunos a idéia de que práticas como a tradução e a memorização de listas de vocabulário, por si só, sem uma preocupação com o desenvolvimento da competência comunicativa, seriam eficazes na aprendizagem, contribuindo para uma perpetuação dessa abordagem no ensino de LE em nossos contextos escolares. 


\section{Conclusões}

Os resultados da análise proposta não me parecem muito animadores. A partir da caracterização das experiências de aprendizagem de língua inglesa dos informantes durante o EM, podemos concluir, como destaca Almeida Filho (2001), que os avanços teóricos, em se tratando do ensino de LE nos últimos anos, parecem ainda não alcançar, de forma efetiva, a sala de aula nos contextos escolares brasileiros.

Observa-se, nos resultados desta pesquisa, uma amostra de uma realidade que parece ainda assolar nossas salas de aula de LE: a perpetuação de mitos e conceitos de ensino de abordagens anteriores, possivelmente cristalizados nas mentes dos professores. Refiro-me, aqui, ao fantasma da Abordagem Tradicional ou Gramática e Tradução que, como se observou nos dados levantados, parece ainda presente nas salas de aula do EM. A meu ver, as experiências advindas dessas práticas podem influenciar a formação de determinadas crenças na mente dos aprendizes, crenças essas que, por sua vez, podem também influenciar as ações desses aprendizes na aprendizagem.

Os problemas que circundam a realidade de ensino-aprendizagem de LE nos contextos escolares nacionais perpassam por questões muito conflitantes, como a falta de material didático, currículos conservadores, falta de competência comunicativa do professor e problemas no processo de formação de professores, como destaca Almeida Filho (2001). No entanto, é necessário que ações no sentido de transformar essa realidade, especificamente no que se refere aos contextos escolares, sejam eles públicos ou privados, surjam de alguma maneira. Acredito que os caminhos para essas mudanças estejam nas propostas para discussões a respeito da realidade atual e nas reflexões quanto ao processo de formação dos professores, reflexões essas que envolvam as experiências anteriores de aprendizagem desses professores e alunos, assim como os contextos social e cultural no nosso sistema educacional, os quais têm contribuído para um processo cíclico de perpetuação de ações equivocadas no ensino de LE no Brasil.

Ressalto a importância do desenvolvimento de pesquisas que busquem conhecer, de maneira mais efetiva, as relações entre as experiências anteriores de aprendizagem, as crenças e as ações, não só dos aprendizes mas também dos professores de LE, pois, certamente, 
tais experiências e crenças podem estar contribuindo para a perpetuação de uma abordagem tradicional no ensino e aprendizagem de LE nos contextos escolares brasileiros.

É fundamental que possamos promover, não apenas no âmbito dos cursos de formação inicial de professores mas também da formação continuada dos professores em serviço, discussões acerca da importância de os professores conhecerem as experiências anteriores de seus alunos. Os professores devem também ser levados a refletir a respeito de suas próprias experiências e crenças de aprendizagem e da maneira como essas experiências têm influenciado sua abordagem de ensinar.

\section{Referências Bibliográficas}

ALMEIDA FILHO, J. C. P. O ensino de línguas no Brasil de 1978: e agora? Revista brasileira de Linguistica Aplicada, v.1, n.1, p. 15-29, 2001.

ALMEIDA FILHO, J. C. P. A abordagem orientadora da ação do professor. In: ALMEIDA FILHO, J. C. P. (Org.). Parâmetros Atuais para o Ensino de Português como Lingua Estrangeira. Campinas: Pontes Editores, 1997.

BARCELOS, A. M. F. Understanding teachers' and students' language learning beliefs in experience: a Deweyan approach. 2000. Tese (Doutorado em ensino de inglês como segunda língua) - College of Education, The University of Alabama, Tuscaloosa.

CANALE, M.; SWAIN, M. Theoretical bases of communicative approaches to second language teaching and testing. Applied Linguistics, v.1, n.1, p. 147, 1980.

CONCEIÇÃO, M. P. Vocabulário e consulta ao dicionário: analisando as relações entre experiências, crenças e ações na aprendizagem de LE. 2004. Tese (Doutorado em Lingüística Aplicada) - Universidade Federal de Minas Gerais, Belo Horizonte.

DAVIS, K. Qualitative theory and methods in Applied Linguistics research. Tesol Quartely, v. 29, n. 03, p. 455-472, 1995.

DEWEY, J. How we Think. Lexington, MA: D.C. Heath, 1933.

DEWEY, J. Experience and Education. New York: Macmillan, 1938. 
ELBAUM, B. E.; BERG, C.A.; DODD, D. H. Previous learning experiences, strategy beliefs, and task definition in self-regulated foreign language learning. Contemporary Educational Psychology, v.18, n.3, p. 318-336, 1993.

HORWITZ, E. K. Surveying students' beliefs about language learning. In: WENDEN,A.; RUBIN, J. (Ed). Learner strategies in language learning. London: Prentice Hall, 1987. p. 110-129.

HORWITZ, E. K. The beliefs about language learning of beginning university foreign language students. The Modern Language Jounal, v. 72, n. 3, p. 283294, 1988.

JOHNSON, D. M. Approaches to research in Second Language Learning, New York, Longman, 1992.

LARSEN-FREEMAN, D.; LONG, M. H. An Introduction to Second Language Acquisition Research. London: Longman, 1991.

MICCOLI, L. S. Learning English as a foreign language in Brazil: a joint investigation of learners' classroom experiences. Unpublished Phd Thesis. University of Toronto, 1997.

NEVES, M. S. Os mitos de abordagens tradicionais e estruturais ainda interferem na prática de sala de aula. In: PAIVA, V. L. M. de O. (Org.). Ensino de lingua inglesa: reflexões e experiências, 1996. p. 69-81.

NUNAN, D. Research Methods in Language Learning. Cambridge: Cambridge University Press, 1992.

OXFORD, R. Language Learning Strategies. Boston: Heinle \& Heinle Publishers, 1990.

SAVIGNON, S. Communicative competence: theory and classroom practice. Massachussets: Addison-Wesley Publishing Co., 1983.

SCARAMUCCI, M. V. R. A Dicotomia Quantitativo/Qualitativo na Pesquisa em Lingüística Aplicativa: Paradigmas Opostos ou Métodos Complementares. Anais do $4^{\circ}$ Congresso Brasileiro de Lingüistica Aplicada. Campinas, UNICAMP, 1995. p. 510-518.

SCHOMMER, M. Effects of beliefs about the nature of knowledge on comprehension. Journal of Educational Psychology, v. 82, p. 498-504, 1990.

SELIGER, H. W.; SHOHAMY, E. Second language research methods. Oxford: Oxford University Press, 1990.

STODOLSKY, S. The subject matters. Chicago: University of Chicago Press, 1988. 


\section{Anexo A}

\section{Questionário de crenças e experiências de aprendizagem}

\section{Questões de 09 a 12}

9. Descreva sua experiência de aprendizagem de inglês no Ensino Médio.

10. Quais eram as atividades realizadas com mais freqüência na sala de aula no Ensino Médio? tradução exercícios gramaticais listas de vocabulário

outras

11. Qual era a orientação dos professores em relação às palavras desconhecidas em um texto?

12. Que aspectos na sua experiência anterior com a aprendizagem de língua inglesa no Ensino Médio você gostaria que não se repetissem na universidade?

\section{Anexo B}

\section{Roteiro para a entrevista semi-estruturada}

1. Você gosta de estudar inglês?

2. Conte-me a respeito da sua experiência de aprendizagem da língua inglesa no Ensino Médio.

3. Você gostaria de fazer alguma observação a respeito das suas respostas aos questionários? 